\title{
ALTERAÇÕES DE ATRIBUTOS DO SOLO PELA CALAGEM SUPERFICIAL E INCORPORADA A PARTIR DE PASTAGEM NATURAL ${ }^{(1)}$
}

\author{
D. S. RHEINHEIME ${ }^{(2)}$, E. J . S. SANTOS ${ }^{(3)}$, J . KAMINSKI ${ }^{(2)}$, \\ E. C. BORTOLUZZI ${ }^{(3)} \&$ L. C. GATIBONI ${ }^{(3)}$
}

\begin{abstract}
RESUMO
A aplicação superficial de calcário pode ser uma alternativa para a correção da acidez do solo sob plantio direto. Este trabalho avaliou as modificações em alguns atributos químicos provocadas pela aplicação de calcário superficial e incorporado ao solo a partir de pastagem natural. 0 experimento foi feito na área Experimental do Departamento de Solos da Universidade Federal de Santa Maria (RS), num Argi ssolo Acinzentado distrófico plíntico. Os tratamentos, com $0,0,2,0,8,5$ e 17,0 t ha-1 de calcário incorporado na camada de $0-20 \mathrm{~cm}$ e em superfície, foram distribuídos em blocos ao acaso, com quatro repetições. Aos 24 meses, reaplicou-se em superfície a dose no tratamento de 2,0 t ha-1. Aos 6, 18, 36 e 48 meses da aplicação do calcário, coletaram-se amostras de solo nas profundidades de 0,0-2,5; 2,5-5,0; 5,0-10,0 e 10,0-15,0 cm. Avaliaram-se os atributos químicos relacionados com a acidez do solo. A correção da acidez do solo foi proporcional à dose de calcário aplicada, independentemente do modo de aplicação. A aplicação de calcário superficial criou uma frente de correção da acidez em profundidade proporcional à dose e ao tempo. Foram necessários 36 meses para que a saturação com alumínio atingisse nível próximo de zero na camada de 0,0-2,5 cm com a aplicação de 2,0 +2,0 t ha-1; 36 meses para a camada 2,5-5,0 cm com 8,5 t ha-1; e 48 meses para a camada 5,0-10,0 cm com 17,0 t ha-1.
\end{abstract}

Termos de indexação: acidez, movi mentação de cátions, bioporos, plantio direto.

(1) Recebido para publicação em novembro de 1999 e aprovado em julho de 2000.

(2) Professor do Departamento de Sol os da Universidade Federal de Santa Maria - UFSM. Caixa Postal 221, CE P 97105-900 Santa Maria (RS). Danilo@ccr.ufsm.br

(3) Engenheiro-Agrônomo, MSc em Agronomia - Biodinâmica de Solos. Universidade Federal de Santa Maria - UFSM. Caixa postal 221, CEP 97105-900 Santa Maria (RS). 


\title{
SUMMARY: CHANGES IN ACID SOIL PROPERTIES BY SUPERFICIAL AND INCORPORATED LIMING ON NATURAL PASTURE
}

\begin{abstract}
Superficial liming is an alternative way to correct soil acidity in no till system. The objective of this study was to evaluate the effects of superficial and incorporated liming on native pasture. The experiment was carried out at the experimental field of theSoil Science Department, at the UniversidadeF ederal deSanta Maria (Brazil), on a Plinthaquult medium textureand with high potential acidity under native pasture. Limerates of 0.0, 2.0, 8.5 and $17.0 \mathrm{Mg} \mathrm{ha}^{-1}$ were used. On half of the plots lime was mixed with the topsoil by disk plow and left on thesurfaceon theother half of the pl ot. Theexperimental design was arranged in completely randomized bl ocks with four replications. After $6,18,36$, and 48 months, soil was sampled at four depths, 0.0-2.5, 2.5-5.0, 5.0-10.0 and 10.0-15.0 cm and the attributes related to soil acidity evaluated. Thesurfaceapplied lime was effective in neutral izing soi I acidity, at a depth proportional to the rate and time. With $2.0+2.0 \mathrm{t} \mathrm{ha}^{-1}$, aluminum saturation reached near zero $(0.0-2.5 \mathrm{~cm}$ layer $)$ at 36 months; with $8.5 \mathrm{t} \mathrm{ha}^{-1}$, it reached near zero $(2.5-5.0 \mathrm{~cm})$ at 36 months; with $17.0 \mathrm{t} \mathrm{ha}^{-1}$ it reached near zero $(5.0-10.0 \mathrm{~cm})$ at 48 months.
\end{abstract}

Index terms: acidity, movement of cations, bi oporous, no-tillagesystem.

\section{NTRODUÇÃO}

O plantio direto (SPD) difere, fundamentalmente, do sistema de cultivo convencional (SCC) pelo manejo do solo; visto que, no primeiro, não há revolvimento e a área permanece coberta pelos restos da cultura anterior ou por vegetação cultivada. No entanto, em ambos os sistemas, há necessidade da adição dos insumos, especial mente cal cário, pois os solos cultiváveis, em sua maioria, são ácidos e necessitam de corretivos da acidez. A utilização do SPD tem aumentado exponencial mente nos últimos anos, quer ocupando as áreas que vinham sendo cultivadas no SCC, quer com pastagens naturais geral mente utilizadas com a exploração da pecuária. Os solos com pastagens naturais, de modo geral, apresentam elevada acidez, com a presença de alumínio e manganês trocáveis em quantidades prejudiciais às plantas eteores de fósforo deficientes, havendo necessidade da adição de insumos para minimizar estes óbices.

NoSCC, a correção da aci dez do solo pressupõea incorporação do calcário ao solo, revolvendo-o com aração e gradagens (CFS RS/SC, 1995). Essa prática altera algumas características físicas do solo, diminuindo a porosi dade, a distribuição de tamanho e a estabilidade dos agregados, além de destruir os canais resultantes da expansão radicular e da atividade biológica, o que prejudica a infiltração de água, aumentando o escorrimento superficial e facilitando a erosão (Fucks et al., 1994). I sso é preocupante, considerando serem necessários, aproximadamente, três anos deSPD para recuperar de 50 a $90 \%$ dos agregados destruídos pela mobilização do solo (Cargnelutti et al., 1996).
Como no SPD a mobilização do solo é mínima, não é possível incorporação do corretivo da acidez ou outros insumos, razão por que devem ser aplicados superficialmente quando necessários. Apesar da baixa solubilidade desse material, tem-se observado a formação de uma frente al cal inizante, que avança lentamente, neutralizando a acidez na subsuperfície (Caires et al., 1998; Amaral, 1998). A pequena mobilização que ocorre somente na linha de semeadura possibilita incorporação do cal cário nesta região, e, com os repetidos ciclos de plantio, pode auxiliar a movimentação descendente de suas partículas, mas não além da profundidade de semeadura.

Também a decomposição dos resíduos vegetais depositados na superfície do solo deve originar compostos orgânicos hidrossolúveis, que complexam o cálcio, permitindo a sua percolação. A presença de alumínio provoca troca com o cálcio, por causa da maior afinidade daquele, diminuindo a fração de alumínio fitotóxico e aumentando o teor de cálcio na solução (Miyazawa et al., 1992, 1996; Oliveira \& Pavan, 1996). Os ânions, como nitratos, sulfatos, cloretos e silicatos presentes, originados da decomposição dos resíduos culturais ou da adição de fertilizantes, também contribuem para a percolação do cál cio e magnésio e, em menor grau, de outros cátions (Pearson et al., 1962; Blevins et al., 1977; Caires et al., 1998; Amaral, 1998).

Caires et al . (1998) observaram, já aos doze meses da aplicação de calcário na superfície de um L atossol o Vermelho-Escurotextura média do estado do Paraná, aumento do pH e dos teores de $\mathrm{Ca}$ e Mg trocáveis e diminuição do Al trocável até à profundidade de $10 \mathrm{~cm}$. Esse efeito prolongou-se com o tempo para as doses maiores, mas o calcário 
continuou reagindo até os 28 meses depois de sua aplicação, oqueé pertinente, pois sua máxima reação geralmente ocorre entre 15 e 36 meses da aplicação (Oliveira et al., 1997). Pöttker \& Ben (1998) também constataram, para Latossol os cultivados sob SPD no estado do Rio Grande do Sul, correção da acidez até os 5 e $10 \mathrm{~cm}$ de profundidade, aos 12 e 36 meses da aplicação superficial do calcário, respectivamente. A ação do tempo na correção em subsuperfície foi mais pronunciada para doses maiores.

O objetivo deste estudo foi avaliar o efeito da aplicação superficial eincorporada de calcárioao solo de pastagem natural, estimado pelas alterações nos atributos quími cos rel acionados com a acidez do solo.

\section{MATE RIAL E MÉTODOS}

O experimento foi realizado no campo experimental do Departamento de Solos da Universidade Federal de Santa Maria (RS), num Argissolo Acinzentado distrófico plíntico textura média rel evo suave ondulado substrato sedimentos recentes aluviais. A área vinha sendo manejada como pastagem natural até 1994, quando da instalação do experimento. Em outubro desse ano, col etaramse amostras de solo na camada de $0-20 \mathrm{~cm}$, cujos resultados quími cos foram: $\mathrm{pH}$ em água $=4,4$; índice $\mathrm{SMP}=4,5$ (servindo como base para os tratamentos com cal cário); M.O. $=37 \mathrm{~g} \mathrm{dm}^{-3}$; Al trocável $=3,3 \mathrm{e}$ Ca + Mg trocáveis $=3,7 \mathrm{cmol} \mathrm{dm}^{-3} ; \mathrm{P}$ disponível $=$ $2,3 \mathrm{mg} \mathrm{dm}^{-3}$ eK disponível $=54 \mathrm{mg} \mathrm{dm}^{-3}$.

A vegetação da pastagem natural foi dessecada com glyphosate. Os tratamentos consistiram da aplicação superficial e incorporação do cal cário, com uma aração e duas gradagens (parcela principal), nas doses de 0,0; 2,0; 8,5 e 17,0 t ha-1 (subparcela). A mobilização do sol o para a incorporação do cal cário somente ocorreu na instalação do experimento e, após isso, do mesmo modo que na aplicação superficial, seguiu a adoção de técnicas do plantio direto. Aos 24 meses, reaplicou-se em superfície a dose no tratamento de $2,0 \mathrm{t} \mathrm{ha}^{-1}$. O delineamento experimental utilizado foi o de blocos ao acaso, com quatro repetições. A parcela principal media $12 \times 12 \mathrm{~m}$ e a subparcela $6 \times 12 \mathrm{~m}$.

Cultivaram-se milho, nas safras 94/95 e 96/97; soja, nas safras 95/96 e 97/98, eazevém, nos invernos de $95,96,97$ e 98 . Os resultados das produtividades foram discutidos por Kaminski et al. (2000).

Col etaram-se amostras de sol o com trado cal ador (10 subamostras/subparcela) aos 6, 18, 36 e 48 meses da aplicação do cal cário, nas profundidades de 0,02,$5 ; 2,5-5,0 ; 5,0-10,0$ e 10,0-15,0 cm. O sol o foi seco em estufa a $55^{\circ} \mathrm{C}$ e passado em peneira de $2 \mathrm{~mm}$. Avaliaram-se o pH em água e os teores de $\mathrm{Ca}$, $\mathrm{Mge}$ Al trocáveis (Tedesco et al., 1995). Calculou-se a saturação por Al, considerando a capacidade de troca de cátions efetiva al cançada notratamento respectivo.
Os valores de pH em água, os teores de Ca, Mge Al trocáveis e a saturação por Al foram submetidos à análise de variância, considerando os modos de aplicação como parcela principal, as doses como subparcel as e as camadas de sol o amostradas como subsubparcelas. Também, para detalhar a movimentação do cal cário em profundidade, quando da aplicação superficial, consideraram-se as datas de amostragem como um fator. Por ter ocorrido interação tripla entre modo $x$ dose $x$ camada, em todas as col etas, não se ajustaram regressões para as doses de calcário. Deste modo, as discussões a respeito de doses foram baseadas no seu comportamento genérico. As médias dos modos de aplicação, camadas amostradas e datas das avaliações foram comparadas pelo teste de Tukey $(p<0,05)$.

\section{RESULTADOS E DISCUSSÃO}

Anal isando os dados apresentados no quadro $1 \mathrm{e}$ nas figuras 1, 2, 3 e 4, verificou-se quea incorporação do cal cário proporcionou mais uniformidade na ação do corretivo da acidez, que se mostrou proporcional à dose e profundidade de aplicação. A aplicação de 2,0 t não al terou o pH (Figura 1), mas diminuiu o Al trocável (Figura 2) e elevou os teores de $\mathrm{Ca}$ e $\mathrm{Mg}$ trocáveis (Figuras 3 e 4), resultando na diminuição da saturação por Al de 39 para $36 \%$, na camada de $0,0-2,5 \mathrm{~cm}$, e de 44 para 39\%, na camada de 2,5$5,0 \mathrm{~cm}$, aos 6 meses da aplicação. Aos 18 meses de sua apl icação, ainda foi observada a ação do corretivo, já quetodas as características estimadas mostraram alterações à avaliação anterior, mas com a mesma tendência. O decréscimo na saturação aos 36 e 48 meses deve ser creditado à reaplicação superficial de mais 2,0 t ha-1 aos 24 meses, o que também deve ter contribuído para o leve decréscimo na saturação por alumínio até $10 \mathrm{~cm}$.

Com a metade da dose recomendada (8,5 t ha-1), o valor de $\mathrm{pH}$ el evou-se e permaneceu em torno de 5,2 até os 36 meses, diminuindo para menos de 5,0 aos 48 meses (Figura 1). Também os teores de Al trocável foram afetados, diminuindo gradativamente de 3,0 para $0,5 \mathrm{cmol} \mathrm{dm}^{-3}$ dos 6 aos 36 meses da aplicação, e tornou a aumentar aos 48 meses da aplicação (Figura 2). Destemodo, pode-se inferir que o efeito residual da metade da dose recomendada prolongou-se pelo período de 36 a 48 meses. Comportamento similar foi observado nos teores de Ca e Mg trocáveis, que aumentaram atéos 36 meses e diminuíram aos 48 meses da aplicação (Figuras 3 e 4). I sto pode ser atribuído ao fato de que, em ambientes com chuvas bem distribuídas, como no sul do Brasil, a maior reação do cal cário no solo se dá entre os 15 e 36 meses após sua aplicação (Oliveira et al., 1997). Todavia, a saturação por alumínio manteve-se até os 48 meses (Quadro 1). 
Quadro 1. Saturação por alumínio aos 6, 18, 36 e 48 meses da aplicação de calcário superficial ou incorporado ao solo sob pastagem natural

\begin{tabular}{|c|c|c|c|c|c|c|c|c|}
\hline \multirow{3}{*}{ Calcário } & \multicolumn{8}{|c|}{ Camada (cm) } \\
\hline & \multicolumn{4}{|c|}{ Incorporado } & \multicolumn{4}{|c|}{ Superficial } \\
\hline & $0-2,5$ & $2,5-5$ & 5-10 & $10-15$ & $0-2,5$ & $2,5-5$ & 5-10 & 10-15 \\
\hline \multirow[t]{2}{*}{$\mathrm{t} \mathrm{ha-1}^{-1}$} & & & & 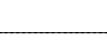 & 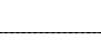 & , & & 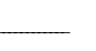 \\
\hline & \multicolumn{8}{|c|}{6 meses após a calagem } \\
\hline $\begin{array}{r}0,0 \\
2,0 \\
8,5 \\
17,0\end{array}$ & $\begin{array}{r}39 \\
36 \\
16 \\
5\end{array}$ & $\begin{array}{r}44 \\
39 \\
13 \\
9\end{array}$ & $\begin{array}{l}42 \\
32 \\
17 \\
14\end{array}$ & $\begin{array}{l}54 \\
47 \\
39 \\
21\end{array}$ & $\begin{array}{r}36 \\
7 \\
1 \\
1\end{array}$ & $\begin{array}{l}37 \\
37 \\
27 \\
14\end{array}$ & $\begin{array}{l}49 \\
49 \\
49 \\
43\end{array}$ & $\begin{array}{l}58 \\
58 \\
57 \\
57\end{array}$ \\
\hline 17,0 & \multicolumn{8}{|c|}{18 meses após a calagem } \\
\hline $\begin{array}{r}0,0 \\
2,0 \\
8,5 \\
17,0\end{array}$ & $\begin{array}{r}36 \\
28 \\
6 \\
0\end{array}$ & $\begin{array}{r}43 \\
33 \\
12 \\
1\end{array}$ & $\begin{array}{r}44 \\
27 \\
14 \\
5\end{array}$ & $\begin{array}{l}55 \\
47 \\
26 \\
15\end{array}$ & $\begin{array}{r}34 \\
3 \\
0 \\
0\end{array}$ & $\begin{array}{r}36 \\
29 \\
5 \\
1\end{array}$ & $\begin{array}{l}47 \\
45 \\
37 \\
25\end{array}$ & $\begin{array}{l}60 \\
53 \\
55 \\
54\end{array}$ \\
\hline 17,0 & \multicolumn{8}{|c|}{36 meses após a calagem } \\
\hline $\begin{array}{r}0,0 \\
2,0 \\
8,5 \\
17,0\end{array}$ & $\begin{array}{r}34 \\
14 \\
4 \\
2\end{array}$ & $\begin{array}{r}45 \\
19 \\
11 \\
2\end{array}$ & $\begin{array}{r}50 \\
32 \\
12 \\
1\end{array}$ & $\begin{array}{r}59 \\
42 \\
27 \\
8\end{array}$ & $\begin{array}{r}29 \\
1 \\
0 \\
0\end{array}$ & $\begin{array}{r}45 \\
26 \\
2 \\
0\end{array}$ & $\begin{array}{l}56 \\
44 \\
35 \\
10\end{array}$ & $\begin{array}{l}59 \\
60 \\
57 \\
41\end{array}$ \\
\hline 17,0 & \multicolumn{8}{|c|}{48 meses após a calagem } \\
\hline $\begin{array}{r}0,0 \\
2,0 \\
8,5 \\
17,0\end{array}$ & $\begin{array}{r}38 \\
4 \\
11 \\
1\end{array}$ & $\begin{array}{r}49 \\
13 \\
11 \\
1\end{array}$ & $\begin{array}{r}56 \\
25 \\
14 \\
2\end{array}$ & $\begin{array}{r}62 \\
50 \\
24 \\
6\end{array}$ & $\begin{array}{r}31 \\
1 \\
0 \\
0\end{array}$ & $\begin{array}{r}39 \\
6 \\
0 \\
0\end{array}$ & $\begin{array}{r}55 \\
32 \\
28 \\
2\end{array}$ & $\begin{array}{l}62 \\
61 \\
51 \\
41\end{array}$ \\
\hline
\end{tabular}

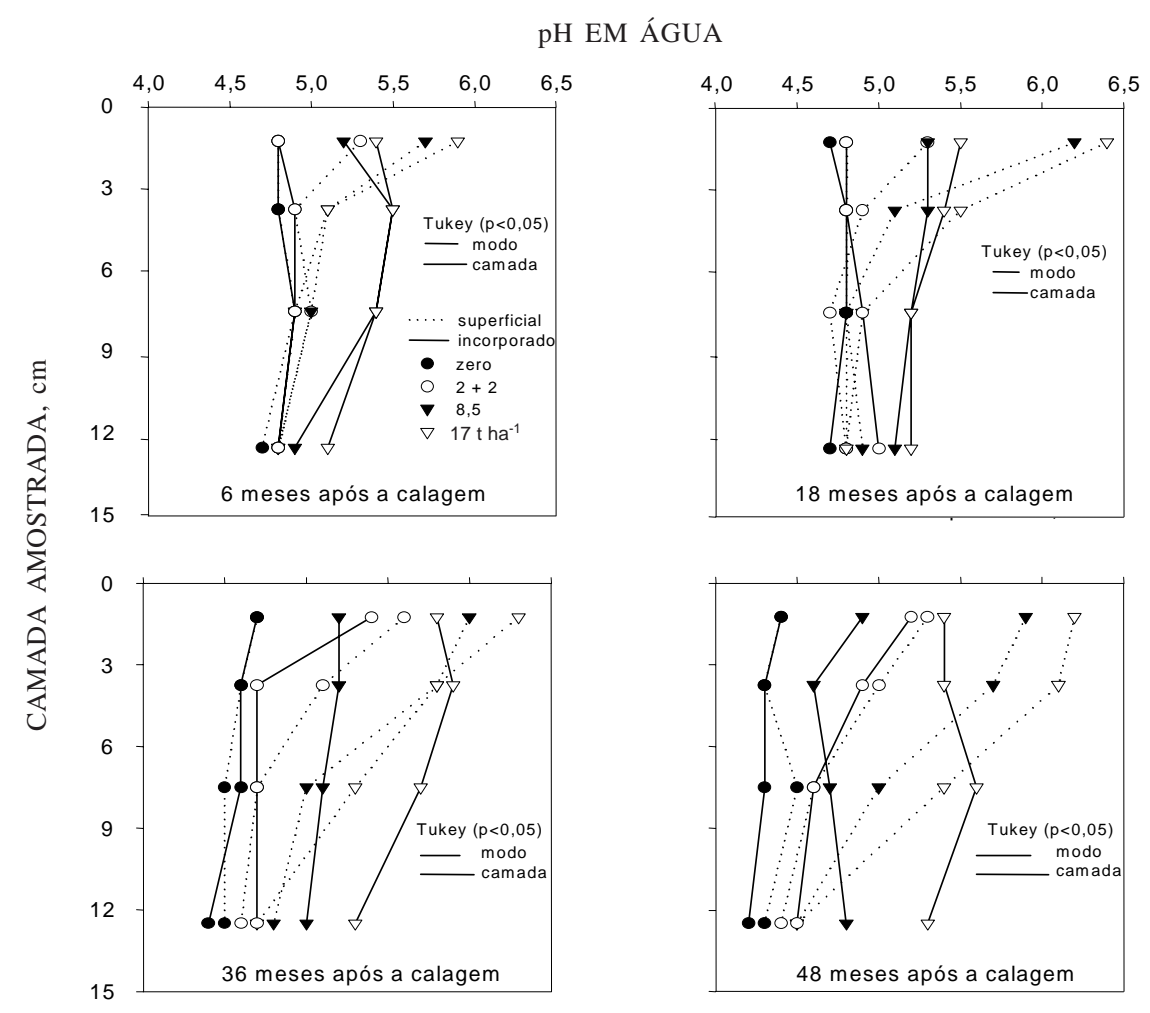

Figura 1. pH em água de diferentes camadas de solo aos 6, 18, 36 e 48 meses da aplicação de calcário superficial ou incorporado ao solo a partir da pastagem natural. 
Mesmo com a incorporação de 17,0 t ha-1 de calcário, dose recomendada para elevar o $\mathrm{pH}$ a 6,0 pelo método SMP, o pH só ultrapassou 5,5 aos 36 meses (Figura 1). O Al trocável somente foi neutralizado na profundidade de $10 \mathrm{~cm}$, após 36 meses, tendendo a elevar seus valores aos 48 meses (Quadro 1 e Figura 2). Os teores de Ca trocável aumentaram de 2,0 para 5,0 $\mathrm{cmol} \mathrm{dm}^{-3}$ até $5 \mathrm{~cm}$ ea $4,0 \mathrm{cmol} \mathrm{dm}^{-3}$ nas camadas mais profundas aos 6 meses da aplicação do cal cário; aos 18 meses, ocorreu um gradiente com a profundidade com $7,8 \mathrm{cmol} \mathrm{dm}^{-3}$, na camada de 0,0-2,5 e 4,0 $\mathrm{cmol} \mathrm{dm}^{-3}$, na camada de 10,0-15,0 cm, o que pode ter ocorrido por não ter a incorporação alcançado $15 \mathrm{~cm}$ de profundidade. Dos 18 aos 36 meses, ocorreu mi gração do $\mathrm{Ca}$ das camadas superficiais para as mais profundas, o que eqüivaleu a, aproximadamente, $1,7 \mathrm{cmol} \mathrm{dm}^{-3}(4,1$ para 5,8$)$ na camada de $10,0-$ $15,0 \mathrm{~cm}$ e uniformizando o teor em todo o perfil. I sto evidencia que, mesmo com a incorporação do cal cário, também ocorreram uma frente alcalinizante e migração de cátions em profundidade.

O comportamento do $\mathrm{Mg}$ foi semelhante ao do $\mathrm{Ca}$, aumentando de 2,0 para, aproximadamente, $4,0 \mathrm{cmol} \mathrm{dm}^{-3} \mathrm{em}$ todas as camadas. Com isso, os val ores de $m$ ficaram, em média, inferiores a $4 \%$ até à profundidade de $10 \mathrm{~cm}$ e a $13 \%$ na camada de 10-15 cm (Quadro 1).
Aos seis meses da aplicação de cal cário no sol o a partir da pastagem natural, o pH e os teores de Ca e Mg trocáveis foram maiores e o deAl trocável menor na camada de $0,0-2,5 \mathrm{~cm}$, quando o corretivo foi deixado na superfície, comparativamente à sua incorporação com aração e gradagem, independentemente da dose (Figuras 1, 2, 3 e 4). Na camada de $2,5-5,0 \mathrm{~cm}$, os atributos avaliados não foram afetados pel os modos de aplicação do corretivo. A partir dos $5 \mathrm{~cm}$ de profundidade, as doses de 8,5 e 17,0 t ha-1 proporcionaram melhores efeitos na correção da acidez quando incorporadas ao solo.

Aos 18 meses, de modo similar ao observado aos seis meses, o pH eos teores deCa eMg trocáveis foram maiores e os de Al menores na camada de 0,0-2,5 cm, quando o calcário foi aplicado superficialmente, comparado à incorporação, independentemente da dose utilizada. A partir dos $5 \mathrm{~cm}$, a incorporação de doses mais elevadas manteve os atributos relacionados com acidez em níveis mais favoráveis ao crescimento radicular. Quando aplicado superficial mente, nesse período de avaliação, a dose de 17,0 t ha-1 el evou o $\mathrm{pH}$ a valores superiores a 5,5 até $5 \mathrm{~cm}$ de profundidade (Figura 1).

Aos 36 meses, o efeito do calcário aplicado superficial mentenas maiores doses ena reaplicação de 2,0 t ha-1 aos 24 meses, atingiu os valores de $\mathrm{pH}$, Ca e Mg trocáveis superiores na camada de 0,0-

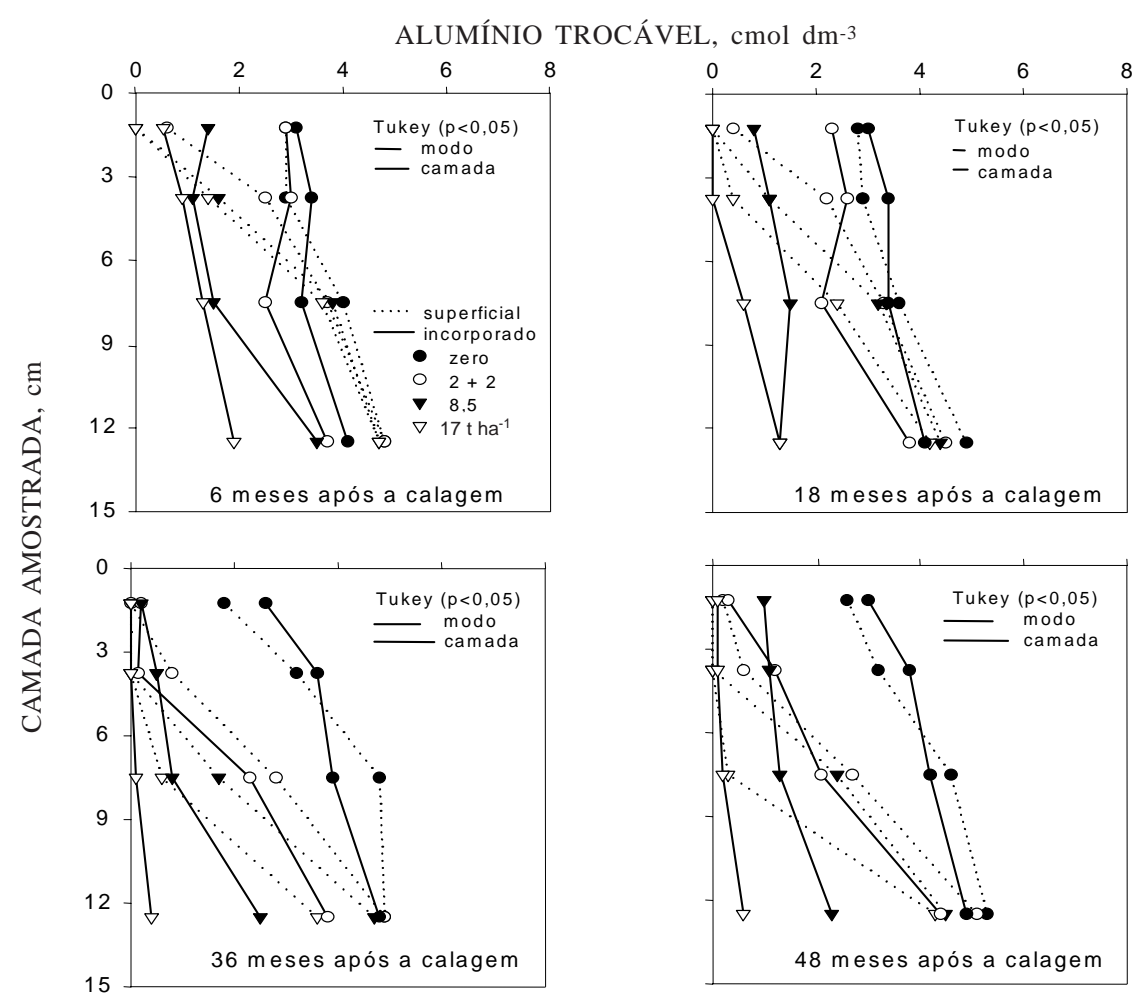

Figura 2. Alumínio trocável de diferentes camadas de solo aos 6, 18, 36 e 48 meses da aplicação de calcário superficial ou incorporado ao solo a partir da pastagem natural. 
2,5 cm, ao incorporado (Figuras 1, 3 e4). O Al trocável foi neutralizado até $5 \mathrm{~cm}$, mas os valores permaneceram maiores do que nos tratamentos incorporados nas camadas mais profundas (Figura 2). A aplicação superficial de 17,0 t ha-1 aumentou o teor de Ca trocável na camada de 5,0$10,0 \mathrm{~cm}$, cujo teor já foi semelhante ao de calcário incorporado ( $\pm 6 \mathrm{cmol} \mathrm{dm}^{-3}$ ). Empregando a metade da dose, os teores de Ca trocável $\left(3,5 \mathrm{cmol} \mathrm{dm}^{-3}\right)$, embora tenham sido maiores do que os da testemunha $\left(2,0 \mathrm{cmol} \mathrm{dm}^{-3}\right)$, ainda foram inferiores aos do cal cário incorporado $\left(5,0 \mathrm{cmol} \mathrm{dm}^{-3}\right)$. O mesmo comportamento foi observado para o Mg trocável. Abaixo de $5 \mathrm{~cm}$ de profundidade para $\mathrm{pH}$ e de $10 \mathrm{~cm}$ para Al, Ca eMg trocáveis, a incorporação do cal cário mostrou efeitos mais pronunciados do que a aplicação superficial.

Aos 48 meses, a aplicação superficial de 8,5 e 17,0 t ha $^{-1}$ manteve o $\mathrm{pH}$ mais el evado do que quando incorporado, atéà profundidade de $5 \mathrm{~cm}$. Na camada de 5,0-10,0 cm, os modos de aplicação se equivaleram e os valores de $\mathrm{pH}$ atingiram 4,6, 5,0 e 5,6, para $2,0+2,0,8,5$ e 17,0 t ha-1, respectivamente. Abaixo desta camada, o pH praticamente não se alterou, permanecendo inferior ao al cançado na incorporação (Figura 1).
Os teores de Al trocável foram semel hantes nos dois modos de aplicação de calcário na camada de 0,0-10,0 cm, porém, na dose mais alta, o teor foi próximo a zero. Na camada de $10,0-15,0 \mathrm{~cm}$, a aplicação superficial não diminuiu o Al e a incorporação neutralizou-o parcial mente (Figura 2).

Os teores de Ca trocável, quando da aplicação superficial, foram mais altos do que quando da incorporaçãoaté 5 an de profundidade, para as doses mais baixas, e até $10 \mathrm{~cm}$ para $17,0 \mathrm{t}^{-1}(7,8 \mathrm{e}$ $5,9 \mathrm{cmol} \mathrm{dm}^{-3}$, superficial e incorporado, respectivamente). Além de $10 \mathrm{~cm}$ de profundidade, após quatro anos, os teores de Ca trocável pouco se alteraram com a aplicação de cal cário superficial.

Nos tratamentos com 2,0 $+2,0$ t ha-1, os teores de Mg trocáveis foram semel hantes entre os modos de aplicação, mas foram superiores aos da testemunha até $10 \mathrm{~cm}$ de profundidade. Com a aplicação superficial de doses mais el evadas (8,5 e 17,0 t ha-1), os níveis de Mg trocável foram maiores somente nos primeiros $5 \mathrm{~cm}$ e menores abaixo de $10 \mathrm{~cm}$, comparativamente à incorporação do calcário (Figura 4).

Destemodo, a aplicação superficial de2,0+2,0 t ha-1 de calcário no solo neutralizou o Al somente aos

CÁLCIO TROCÁVEL, cmol dm-3
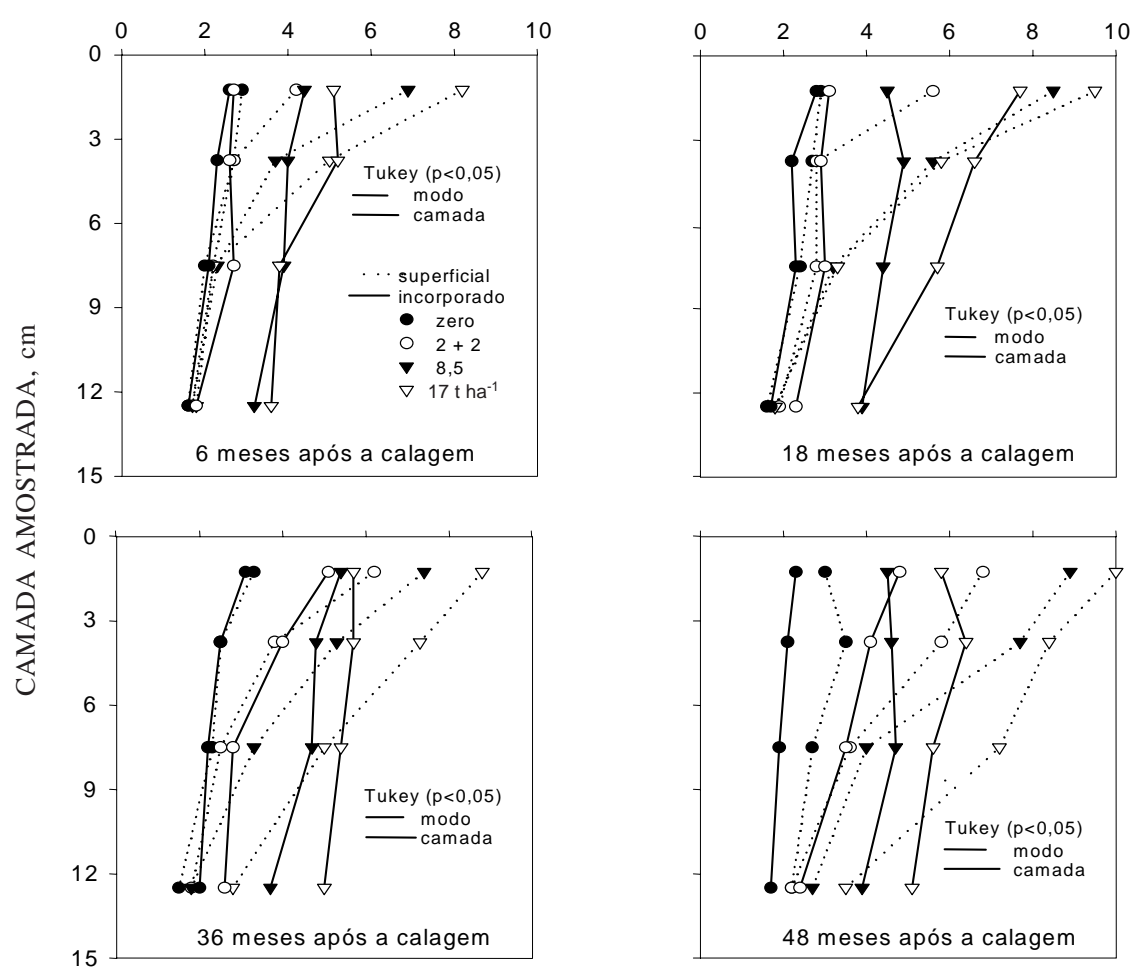

Figura 3. Cálcio trocável de diferentes camadas de solo aos 6, 18, 36 e 48 meses da aplicação de calcário superficial ou incorporado ao solo a partir da pastagem natural. 
36 meses e limitou-se à camada de 0,0-2,5 cm; com $8,5 \mathrm{t} \mathrm{ha}^{-1}$, aos seis meses na camada de $0,0-2,5 \mathrm{~cm}$ e aos 36 meses na camada de 2,5-5,0 cm; com 17,0 t ha-1, aos seis meses na camada de $0,0-2,5 \mathrm{~cm}$, aos 18 meses na camada de $2,5-5,0 \mathrm{~cm}$ e aos 48 meses na camada de 5,0-10,0 cm (Quadro 1).

Os resultados obtidos nestetrabal hotêm seguido a mesma tendência observada por outros autores, que encontraram mel horias nos atributos químicos do solo com a aplicação superficial de calcário no SPD sobre pastagem natural (Coventry et al., 1992; Caires et al., 1998; Amaral, 1998; Pöttker \& Ben, 1998; Pöttker et al., 1998; Caires et al., 1999; Rheinheimer et al., 2000).

À medida que aumentou a dose de calcário aplicado na superfície do solo, a correção da acidez em profundidade foi maior, porém a incorporação teve efeito imediato. Não ocorreu migração dos efeitos da calagem no perfil do solo quando a quantidade aplicada em superfície foi menor do que a necessidade para neutralizar o Al trocável das camadas adjacentes. Os efeitos da calagem só ocorreram em profundidade após o pH na zona de dissolução do calcário ter atingido valores de 5,2 a 5,5. A dissociação do calcário, em solo ácido, promoveu a liberação de ânions $\left(\mathrm{OH}^{-}\right.$e $\left.\mathrm{HCO}_{3}^{-}\right)$, os quais reagiram com os cátions de reação ácida da solução do solo $\left(\mathrm{H}^{+}, \mathrm{Al}^{3+}, \mathrm{Fe}^{2+}, \mathrm{Mn}^{2+}\right)$, e essa reação ocorreu até pH em torno de 5,5. Enquanto existirem esses cátions ácidos, a reação de neutralização da acidez ficará limitada à camada superficial, retardando o efeito na subsuperfície. Para que a neutralização da acidez ocorra na subsuperfície, os produtos da dissociação do calcário têm de ser arrastados para as camadas inferiores.

Dentre os fatores que podem contribuir para a migração do calcário e dos produtos de sua reação noSPD, destaca-sea preservação das características físicas e do ambiente. A não-mobilização do solo e a sua cobertura com o predomínio degramíneas estivais mantêm os canais contínuos construídos e estabilizados pela atividade biológica, o que permite maior infiltração deágua (Eltz et al., 1989), queestá normalmente enriquecida com os produtos da dissoluç̧ão do calcário, neutralizando a acidez e aumentando os cátions de reação básica em profundidade. Também poderá ocorrer o arrastamento de partículas finas de cal cário pela água de infiltração nos macrocanais biol ógicos, ou incorporação bi ológica do calcário pela ação da macrofauna do solo, como minhocas e insetos. Entretanto, considerando a baixa sol ubilidade do cal cário e a grande necessi dade para corrigir a acidez do solo em subsuperfície, essa contribuição deve ser pequena.
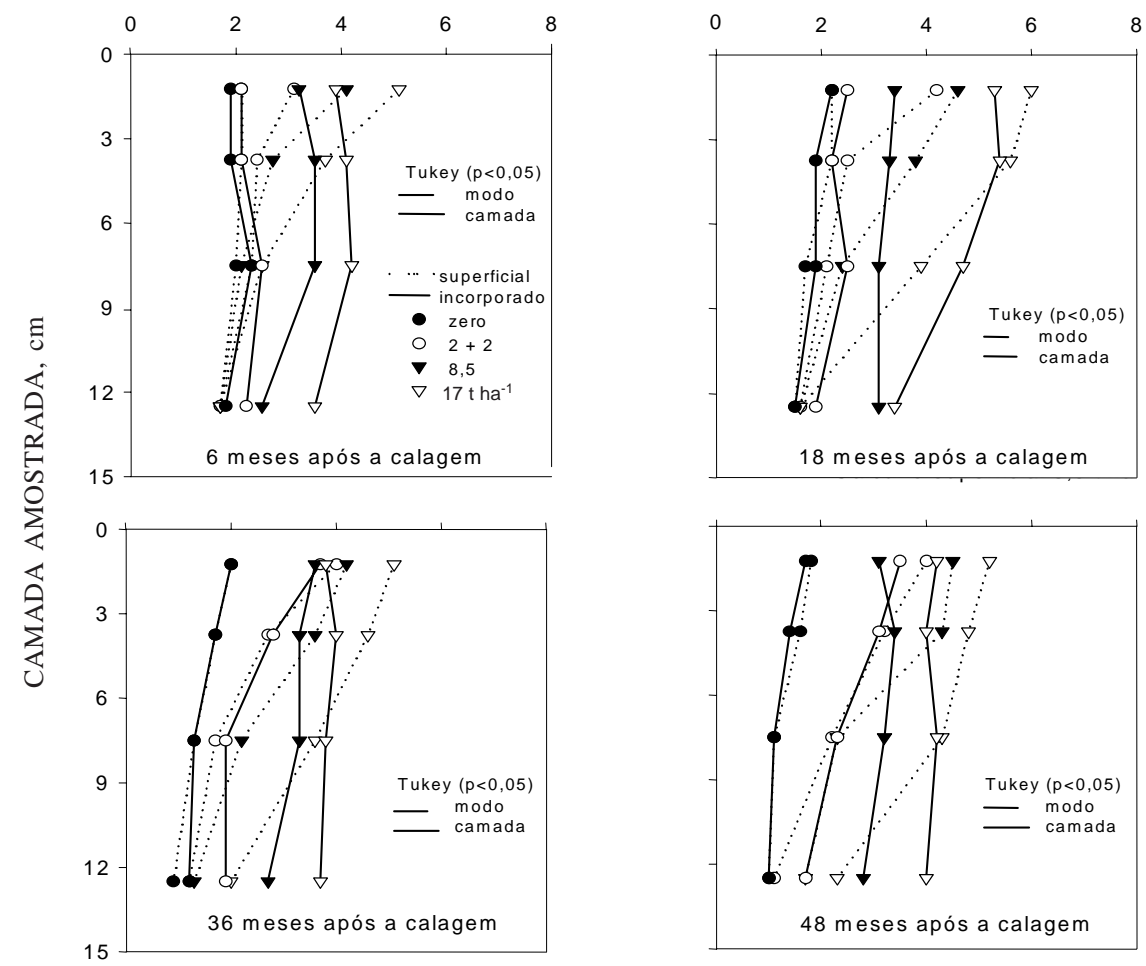

Figura 4. Magnésio trocável de diferentes camadas de solo aos 6, 18, 36 e 48 meses da aplicação de calcário superficial ou incorporado ao solo a partir da pastagem natural. 
A formação de compl exos entreas substâncias orgânicas hidrossolúveis e o Ca eo Mg na superfície do solo e a posterior troca desses cátions pelo alumínio em camadas mais profundas são, segundo Miyazawa et al. (1992, 1996) e Oliveira \& Pavan (1996), responsáveis pela neutral ização da acidez em profundidade. Pode-se atribuir tal fato à melhor constância, à maior concentração deânions orgânicos eà intensa atividade biológica da camada superficial do solo sob pastagem natural ou SPD, que fornece substâncias orgânicas quelantes com maior afinidade pelo alumínio do que pelo cálcio e magnésio. Tais substâncias são produzi das, em geral, pel as plantas e li beradas durante sua decomposição. Considerando a grande variabilidade entre as plantas (Santos et al., 1999), é interessante introduzir no sistema de rotação as que maximizem a correção da aci dez em subsuperfície, possibilitando a utilização dos solos ácidos ocupados por pastagens naturais para a produção deculturas comerciais sem o revolvimento do solo para a incorporação do calcário.

\section{CONCLUSÕES}

1. A correção da acidez do solo mostrou-se proporcional à dosedecal cárioaplicada, independentemente do modo de aplicação.

2. A aplicação de calcário superficial criou uma frente al calinizante que avançou em profundidade proporcional mente à dose e ao tempo empregados: com 2,0 +2,0 t ha-1, a saturação por alumínio foi próxima de zero somente na camada de $0,0-2,5 \mathrm{~cm}$ aos 36 meses; com 8,5 t ha-1 ${ }^{-1}$, foi zero na camada de $0,0-2,5 \mathrm{~cm}$ ( 6 meses) e na camada de $2,5-5,0 \mathrm{~cm}$ (36 meses), e com 17,0 t ha-1 foi zero na camada de $0,0-2,5 \mathrm{~cm}$ (6 meses), na camada de $2,5-5,0 \mathrm{~cm}$ (18 meses) ena camada de 5,0-10,0 cm aos 48 meses.

3. O avanço dos efeitos da calagem superficial só ocorreu após a neutral ização da camada de aplicação ou da alcançada pela migração.

\section{LITERATURA CITADA}

AMARAL, A.S. Reaplicação de calcário no plantio direto consolidado. Porto Alegre, Universidade Federal do Rio Grande do Sul, 1998. 102p. (Tese de Mestrado)

BLEVINS, R.L.; THOMAS, G.W. \& CORNELUIS, P.L. Influence of no-tillage and nitrogen fertilization on certain soil properties after 5 years of continuous corn. Agron. J ., 69:383386, 1977.

CAIRES, F.E.; FONSECA, A.F.; MENDES, J .; CHVEIRI, A.W.; MADRUGA, E.F.\& FIGUEIREDO, A. Produção de milho, trigo e soja em função das alterações de características químicas do solo pela aplicação de calcário e gesso na superfície, em sistema de plantio direto. R. Bras. Ci. Solo, 23:315-327, 1999.
CAIRES, F.E.; CHVEIRI, A.W.; MADRUGA, E.F.\& FIGUEIREDO, A. Alterações de características químicas do solo e resposta da soja ao calcário e gesso aplicado na superfície em sistema de cultivo sem preparo do solo. R. Bras. Ci. Solo, 22:27-34, 1998.

CARGNELUTTI, A.F.; REINERT, D.J . \& BORGES, D.F. Recuperação da estabilidade estrutural induzida pelo plantio direto, de sol o que recebeu preparo convencional por dois anos. In: CONGRESSO LATINO-AMERICANO DE CIÊNCIA DO SOLO, 13., Águas de Lindóia, 1996. Trabalhos. Campinas, Sociedade Brasileira de Ciência do Solo, 1996. (CD-ROM)

COMISSÃO DE FERTILIDADE DO SOLO - RS/SC. Recomendação de adubação e calagem para os estados do Rio Grande do Sul e Santa Catarina. 3.ed. Passo Fundo, SBCS - Núcleo Regional Sul/EMBRAPA/CNPT, 1995. 224p.

COVENTRY, D.R.; HIRTH, J .R. \& REEVES, T.G. Interactions of tillage and lime in wheat-subterranean clover rotations on an acidic sandy clay loam in southeastern Australia. Soil Till. Res., 25:53-65, 1992.

ELTZ, F.L.F.; PEIXOTO, R.T.G. \& J ASTER, F. Efeitos de sistemas de preparo do solo nas propriedades físicas e químicas de um Latossol o Bruno álico. R. Bras. Ci. Solo, 13:259-267, 1989.

FUCKS, L.F.; REINERT, D.J .; CAMPOS, B.C.; BORGES, D.F. \& SAPINI, C. Degradação da estabilidade estrutural pela aração e gradagem de solo sob plantio direto por quatro anos. In: REUNIÃO BRASILEIRA DE MANEJ O E CONSERVAÇÃO DO SOLO E DA ÁGUA, 10., Florianópolis, 1994. Anais. Florianópolis, Sociedade Brasileira de Ciência do Solo, 1994. p.196-197.

KAMINSKI, J .; RHEINHEIMER, D.S.; SANTOS, E.J.S.; GATIBONI, L.C.; BORTOLUZZI, E.C. \& XAVIER, F.M. Resposta de culturas à aplicação de calcário em superfície ou incorporado ao solo a partir da pastagem natural. Ci. Rural, 30, 2000 (no prelo).

MIYAZAWA, M.; PAVAN, M.A. \& SANTOS, J .C.F. Effects of addition of crop residues on the leaching of $\mathrm{Ca}$ and $\mathrm{Mg}$ in Oxisols. In: INTERNATIONAL SYMPOSIUM ON PLANT-SOIL INTERACTIONS AT LOW pH, 4, Belo Horizonte, 1996. Abstract. Belo Horizonte, Sociedade Brasileira de Ciência do Solo / EMBRAPA-CPAC, 1996. p.8.

MIYAZAWA, M.; CHIERICE, G.O. \& PAVAN, M.A. Amenização da toxidade de alumínio às raízes do trigo pela complexação com áci dos orgâni cos. R. Bras. Ci. Solo, 16:209-215, 1992.

OLIVEIRA, E.L. \& PAVAN, M.A. Control of soil acidity in notillage system for soybean production. Soil Till. Res., 38:47-57, 1996.

OLIVEIRA, E.L.; PARRA, M.S. \& COSTA, A. Resposta da cultura do milho, em um Latossolo Vermel ho-Escuro álico, à calagem. R. Bras. Ci. Solo, 21:59-64, 1997.

PEARSON, R.W.; ABRUNA, F . \& VICE-CHANCES, J . Effect of lime and nitrogen applications on downward movements of calcium and magnesium in two humid soils of Puerto Rico. Soil Sci., 93:77-82, 1962. 
PÖTTKER, D. \& BEN,J .R. Calagem para uma rotação deculturas no plantio direto. R. Bras. Ci. Solo, 22:675-684, 1998.

PÖTTKER, D.; AMBROSI, I.; BEN, J .R.; KOCHHANN, R.A. \& DENARDIN, J .E. Calagem em plantio direto. Passo Fundo: EMBRAPA-CNPT/Projeto METAS, 1998. 40p. (Boletim Técnico, 4)

RHEINHEIMER, D.S.; SANTOS, E.J .S.; KAMINSKI, J . \& XAVIER, F.M. Aplicação superficial de cal cário no plantio direto consolidado em solo arenoso. Ci. Rural, 30, 2000 (no prelo)
SANTOS, J .C.F.; MEDA, A.R.; CASSIOLATO, M.E.; MIYAZAWA, M. \& PAVAN, M.A. Avaliação biológica do potencial de compostos orgânicos hidrossolúveis de resíduos vegetais de mobilizar cálcio em solos ácidos. In: CONGRESSO BRASILEIRO DE CIÊNCIA DO SOLO, 27., Brasília, 1999. Seção de Poster 9. Viçosa, Sociedade Brasileira de Ciência do Solo, 1999. (CD ROM)

TEDESCO, M.J .; GIANELLO, C.; BISSANI, C.A.; BOHNEN, H. \& VOLKWEISS, S.J. Análises de solo, plantas e outros materiais. Porto Alegre, Universidade Federal do Rio Grande do Sul, 1995. 174p. (Boletim Técnico, 5) 
D. S. RHEINHEIMER et al. 